\title{
COVID-19 in Adults With Dementia: Clinical Features and Predictive Factors of Mortality. A Clinical Cohort Study on 125 Patients
}

Agathe Vrillon ( $\nabla$ agathe.vrillon@aphp.fr)

APHP: Assistance Publique - Hopitaux de Paris https://orcid.org/0000-0002-0761-7885

\section{Elsa Mhanna}

Fondation Léopold Bellan, France

Clément Aveneau

AP-HP: Assistance Publique - Hopitaux de Paris

Manon Lebozec

AP-HP: Assistance Publique - Hopitaux de Paris

Lina Grosset

AP-HP: Assistance Publique - Hopitaux de Paris

Diane Nankam

Fondation Léopold Bellan, France

Fernanda Albuquerque

Fondation Léopold Bellan, France

Raphaelle Razou Feroldi

Fondation Léopold Bellan, France

Barbara Maakaroun

Fondation Léopold Bellan, France

lana Pissareva

Fondation Léopold Bellan, France

Dalenda Cherni Gherissi

Fondation Léopold Bellan, France

Julien Azuar

AP-HP: Assistance Publique - Hopitaux de Paris

Véronique François

AP-HP: Assistance Publique - Hopitaux de Paris

Claire Hourrègue

AP-HP: Assistance Publique - Hopitaux de Paris

Julien Dumurgier

AP-HP: Assistance Publique - Hopitaux de Paris

Lisette Volpe-Gillot 
Fondation Léopold Bellan

\section{Claire Paquet}

AP-HP: Assistance Publique - Hopitaux de Paris

\section{Research}

Keywords: COVID-19, SARS-Cov2, dementia, mortality, prognostic factors

Posted Date: February 18th, 2021

DOl: https://doi.org/10.21203/rs.3.rs-208272/v1

License: (c) (i) This work is licensed under a Creative Commons Attribution 4.0 International License. Read Full License

Version of Record: A version of this preprint was published at Alzheimer's Research and Therapy on April 10th, 2021. See the published version at https://doi.org/10.1186/s13195-021-00820-9. 


\section{Abstract}

\section{BACKGROUND}

There is limited evidence on the characteristics and outcome of patients with dementia hospitalized for novel coronavirus infection (COVID-19).

\section{METHOD}

We conducted a prospective study in 2 gerontologic Covid Units in Paris, France, from March 14 2020 to May $7^{\text {th }}$ 2020. Patients with dementia hospitalized for confirmed COVID-19 infection were systematically enrolled. A binary logistic regression analysis was performed to identify factors associated with mortality at 21 days.

\section{RESULTS}

We included 125 patients. Median age was 86 (IQI 82-90); 59.4\% were female. Most common causes of dementia were Alzheimer's disease, mixed dementia and vascular dementia. $67.2 \%$ had $\geq 2$ comorbidities; $40.2 \%$ lived in a long-term care facility. The most common symptoms at COVID-19 onset were confusion and delirium (82.4\%), asthenia (76.8\%) and fever (72.8\%) before polypnea (51.2\%) and desaturation $(50.4 \%)$. Falls were frequent at the initial phase of the disease (35.2\%). The fatality rate at 21 days was $22.4 \%$. Chronic kidney disease and CRP at admission were independent factors of death. Persisting confusion, mood and behavioral disorders were observed in survivors (19.2\%).

\section{CONCLUSION}

COVID-19 in demented individuals is associated with severe outcome in SARS-CoV-2 infection and is characterized by specific clinical features and complications, with confusion and delirium at the forefront. COVID-19 testing should be considered in front of any significant change from baseline.

\section{Introduction}

On January $30^{\text {th }} 2020$, the World Health Organization (WHO) drew attention to a new coronavirus disease 2019 (COVID-19) declaring it a public health emergency of international concern. As of February the $4^{\text {th }} 2021$, there had been more than 100 millions of cases and 2 millions deaths worldwide. The clinical spectrum of COVID-19 infection appears broad, encompassing asymptomatic infections, mild upper respiratory tract illness and severe pneumonia with respiratory failure, systemic complications and multi-organ failure [1].

Severe COVID-19 affects elderly with chronic diseases, including cognitive decline, in high proportion compared to general adult population [2,3]. According to recent studies, dementia is a major risk factor for COVID-19 severity [4,5]. Concomitantly, the risk of exposure to the infection is more important in patients with dementia, highly exposed in the context of long-term care facilities, frequent 
hospitalizations and intellectual decline. So far, specific clinical features and prognostic factors of COVID-19 in demented patients remain unclear $[6,7]$.

In order to identify specific features and risk factor of death in demented people, we report a cohort study on 125 patients with dementia hospitalized for a confirmed COVID-19 infection.

\section{Methods}

\section{Study design}

This prospective cohort study systematically included patients over 65 with dementia hospitalized for COVID-19 infection in two centers : Leopold Bellan Hospital,Paris, France and Lariboisère Fernand Widal University Hospital Paris, France, between March $14^{\text {th }}$ and May $7^{\text {th }} 2020$. The definite diagnosis of COVID19 was determined through reverse-transcription polymerase chain reaction (RT-PCR) testing of pharyngeal swabs or chest CT. We collected demographics, medical history, clinical presentation, laboratory results, treatment, complications and outcome. The outcome was death at 21 days, to assess short-term case fatality rate. Dementia was defined according to the American Psychiatric Association's Diagnostic and Statistical Manual (DSM-5) as a significant cognitive decline from a previous level of performance in one or more cognitive domains interfering with independence in everyday activities [8]. Etiology of the dementia was collected when available. Comorbidities were evaluated using the Charlson Index [9]. Blood oxygen desaturation was defined by a saturation under $93 \%$ or a loss of $3 \%$ or more. Acute kidney injury was diagnosed according to KDIGO definition [10]. Cardiac injury was diagnosed clinically or throughout, abnormalities observed on electrocardiography and serum level of troponin and Brain natriuretic Peptide (BNP). COVID-19 severity and Acute Respiratory Distress Syndrome were defined following the WHO recommendations. None of the patients included in this study were deemed candidates for the intensive care unit after staff discussions with the physician in charge, palliative care team and patients and caregivers.

\section{Statistical analysis}

Descriptive data are shown as median (interquartile interval) or percentage (number of subjects). Chisquare test or Fisher test was used to compare qualitative data between groups. Mann Whitney test and Kruskal Wallis were applied to analyze non-normally distributed data. A binary logistic regression analysis was performed to identify clinical and demographic characteristics associated with mortality. We included the variables that had differed in descriptive analysis between survivors and non survivors. Variables with missing data were excluded from this analysis. A two-tailed $p$-value $<0.05$ was considered significant. Statistical analysis was performed using GraphPad Prism and SPSS 85 Statistics version 26.0.

Ethical statement: we obtained the required approval from the Commission Nationale Informatique et Liberté (CNIL) to collect anonymized data. 


\section{Results}

We included a total of 125 patients. Patients demographic and clinical characteristics are summarized in Table 1. The median age was 86 (82-91) year-old (yo), and $41.6 \%$ of included subjects were male. All patients had a clinical diagnosis of dementia. $40 \%$ of the patients had received a specific diagnosis: most frequent cause of dementia was Alzheimer's Disease (AD) (10.4\%), vascular dementia (7.2\%), multiple etiologies dementia (7.2\%). Parkinson's disease and atypical parkinsonian syndromes, frontotemporal dementia alcohol related cognitive impairment and psychosis accounted for other diagnoses. Patients frequently presented with associated mood disorder (31.2\%) and psychotic symptoms (12\%). A stroke history was noted in $32 \%$ of patients. A former history of fall was reported for $38.4 \%$ of patients. Sixty percent of patients received psychotropic treatment: antidepressants/mood regulators $(35.2 \%)$, anxiolytic (30.4\%) and neuroleptics (12.0\%). Most patients were living at home (59.2\%) while $40.8 \%$ were living in a long-term care facility.

Non neurological comorbidities were frequent $(91.2 \%)$ with $67.2 \%$ of patients with 3 or more comorbidities. Median Charlson comorbidities index was 6 (5-7). Most frequent comorbidities were hypertension (80\%), dyslipidemia (48.8\%) and history of cardiovascular disease (40.8\%).

\section{Clinical presentation and biological findings}

Infection was confirmed in $93.2 \%$ of patients by PCR test and in $6.8 \%$ by chest CT (Table 2 ). The most common initial symptoms were confusion and delirium observed in $82.4 \%$ of patients. It was notably the only symptom at onset and during the evolution of the disease for three patients in our cohort, thus COVID-19 infection was screened for considering the pandemic context. The most frequent associated general symptoms were asthenia $(76.8 \%)$, fever $(72.8 \%)$ and anorexia $(56.8 \%)$. Most frequent respiratory symptoms were: polypnea (51.2\%), desaturation (50.4\%) and cough (49.6\%). An initial fall was reported in $35.2 \%$. No patient complained of loss of taste or smell.

The most common biochemical abnormality was lymphopenia (84.8\%) with a median value of lymphocytes of 0.99 (0.73-1.29), increased CRP at admission and low albumin. Thrombopenia was observed in $16 \%$ of cases. Troponin was available for 22 patients and increased in $35.5 \%$ of patients.

\section{Treatment and outcome}

Treatment and outcome are reported in Table 3. Persisting behavioral disorders during hospitalization were observed in $19.2 \%$. Other neurological complications included strokes (2.4\%, 3 patients) and seizure (2.4\%, 3 patients). Treatment mostly associated oxygen therapy (60\%) and antibiotherapy (61.6\%). A minority of patients received specific treatment for COVID-19 (hydroxychloroquine $16.8 \%$ and corticosteroids $8.0 \%$ ). ARDS (Acute respiratory distress syndrome) occurred in $25.6 \%$ of patients. Associated complications were bacterial surinfection (19.2\%), acute kidney injury (16.8\%), cardiac failure 
(13.6\%) and diabetic acidoketosis (2.4\%). Treatment by neuroleptics or antidepressant was not associated to outcome.

Mortality at 21 days was $22.4 \%$. The large majority of deaths (92.9\%) were attributed to ARDS. Cardiac failure and osmolar coma were associated causes of death. Non-survivors were overrepresented in men (60.7\% versus $36.1 \%$ in survivors, $P=0.029$ ), presenting more frequent chronic kidney disease. Respiratory distress, lower lymphocytes count, high CRP and positive troponin were more frequent in non-survivors. No statistically significant difference was observed in the rate of death between patients with a diagnosed neurodegenerative disorder compared to the rest of the population $(P=1.000)$ or in those living in long-term facilities $(P=0.663)$.

Male sex, chronic kidney disease, desaturation, dyspnea as well as lymphocytes count, CRP, and serum creatinine at admission were included in a multivariate binary logistic regression model to identify associated factors of death (Table 4). Two variables were independently associated to death at 21 days. CRP at admission: $(\mathrm{OR}=1.013, \mathrm{P}=0.004)$ and chronic kidney disease $(\mathrm{OR}=4.631, \mathrm{P}=0.025)$.

\section{Discussion}

In this study, we aimed at describing specific clinical features and prognostic factors of mortality in demented patients. Confusion with or without general symptoms is the most frequent initial presentation and was not a predictive factor of death while history of chronic kidney disease and CRP level at admission were significantly associated with mortality.

Studies focusing on the neurological features of COVID-19 suggest that confusion occurred in $20-30 \%$ of hospitalized patients increasing to $60-70 \%$ for severe forms $[11,12]$.. Older adults are more prone to experiencing confusion and delirium and dementia is the higher predisposing risk factor (OR from 2.3$4.7)$, before age, visual and hearing impairment, and polypharmacy $[13,14]$. Several series and cases reports highlight COVID-19 infection presenting as isolated and persistent confusion [15-17]and as a factor of negative outcome [18]. In our serie, confusion \& delirium occured independently of the severity of the COVID-19 infection and did not appear as a factor of negative outcome. The discrepancy between all these results could be explained by the high prevalence of confusion in our cohort that might have not allowed to study his weight on prognosis.

Overall, the prevalence of confusion and delirium was higher than the one reported in older adults admitted with non-COVID-19 pneumonia[19,20] and in patients admitted with severe acute respiratory syndrome (SARS) and Middle East respiratory syndrome (MERS)[21].

The pathophysiological explanations remain unclear. COVID-19 could have a direct neuronal toxicity through CNS invasion[22]. Cognitive symptoms could also indirectly be related to neuroinflammation, corresponding to "sickeness behavior" to which demented subjects have been shown to present with increased vulnerability [23]. An increase of neurofilaments lights and Glial Fibrillary Acid Protein, respectively reflecting neuronal injury and glial activation has been observed in patients with moderate 
and severe COVID-19 with or without dementia [24]. The neuronal and synaptic fragility in demented patients may be particularly prone to injury induced by COVID-19, either through direct infectious lesion or through indirect inflammatory mechanisms. Another frequently reported neurologic symptom in our series is falls, as already reported [5,25]. General risk of fall is high in demented older adults; gait impairment and falls are more prevalent in dementia than in normal aging and are related to the severity of cognitive impairment [26]. Rupture of homeostasis in the context of viral infection would account for their frequent occurence [27].

Beside confusion, delirum and falls, a braod range of neurological complications, caused directly or indirectly by the virus, including infectious, para-infectious, and post-infectious encephalitis, stroke related to coagulopathy, and acute neuropathies have been reported [28].

Stroke and seizure were observed during disease evolution for respectively 3 of our patients, at a similar rate as the one observed in cases of a cohort of around 5000 subjects [29].Case fatality rate at 21 days was $22.4 \%$, in line with previous findings in a large cohort [2,5]. A study by Canavelli et al [30] evaluating the prevalence of dementia in a random sample of confirmed COVID-19 infected patients, found that patients with dementia accounted for $15.8 \%$ of overall COVID-19 related death. In a meta-analysis of, the mortality of individuals with dementia was increased compared to not demented subjects (OR=5.17)[31]. More specifically, Matias-Giu et al have shown that AD patients showed a higher risk of death in COVID19 than patients with fronto-temporal dementia. One explanation could be that the APOE e4 genotype (the highest risk factor for $A D$ ) has been reported as a predictive factor of severe COVID-19 [19] and death [20]. In our series, we did not find any difference between patients with a diagnosed dementia (AD, vascular dementia, alcohol related cognitive impairment) and patients with unexplored cognitive impairment.

History of chronic kidney disease and high CRP at admission were independently associated with death. Our overall data are in accordance with previous reports in which male sex, multiple comorbidities, elevated CRP and low lymphocyte count were observed in the majority of COVID-19 deaths [3,32]. None of our patient was deemed suitable candidate for ICU or invasive ventilation. Patients received variable treatment, associating antibiotherapy, rarely antiviral treatment, high flow oxygen and corticosteroids or immunomodulatory drugs for a small number. Given the size of our cohort, we were not able to assess efficiency or draw any recommendation. Therapeutic essays have been ongoing regarding the potential beneficial effect of serotonin reuptake inhibitor (SSRI) through modulation inflammatory response during sepsis[33]; no difference in outcome was observed regarding treatment by antidepressant in our cohort.

All in all, in the actual context of a second wave of COVID-19, this work demonstrates that special attention should be given to demented patients who manifest confusion with acute behavioral changes and falls, with or without asthenia, fever and lymphopenia.

\section{Limitations}


This study has several limitations. Our studied population was drawn from geriatric hospitalized samples of demented patients in need of hospital care, limiting its generalization. Patients presenting with atypical symptoms and lacking respiratory symptoms or fever may not have been identified as COVID cases and included in our analysis. Due to low group numbers, we could not assess the difference in severity and mortality between the different etiologies of dementia. We focused on short-term mortality; long term follow-up could allow us to identify additional prognostic factors.

\section{Conclusion}

In our cohort of individuals with dementia, we have observed that COVID-19 was characterized by atypical presentation with prevalent nonspecific symptoms at the initial phase of the disease, namely persisting confusion and behavioral disorders as well as frequent falls. Early recognition of COVID-19 in demented adults should help provide early treatment and adequate care and isolation and COVID-19 testing should be considered in front of any significant change from baseline.

\section{Declarations}

\section{Ethics approval and consent to participate}

We obtained the required approval from the Commission Nationale Informatique et Liberté (CNIL) to collect anonymized data.

\section{Consent for publication}

Not applicable.

\section{Availability of data and material}

The full datasets used during the current study are available from the corresponding author on reasonable request.

\section{Competing interests}

The authors declare that they have no competing interests

\section{Funding}

The authors received no financial support for the research, authorship and/or publication of this article.

\section{Author's Contributions}

Concept \& design: AV, EM, LVG, CP.

Data acquisition, analysis and interpretation of the data: all authors. 
Statistical analysis: AV, EM, JD.

Drafting the manuscript: AV, EM, CP.

Writing-review \& editing: all authors.

Supervision of the study: CP, LVG.

AV and EM have full access to all the data in the study and take full responsibility for the integrity of the data and the accuracy of the data analysis.

\section{Acknowledgements}

Not applicable.

\section{References}

[1] Wu Z, McGoogan JM. Characteristics of and Important Lessons From the Coronavirus Disease 2019 (COVID-19) Outbreak in China: Summary of a Report of 72314 Cases From the Chinese Center for Disease Control and Prevention. JAMA 2020. https://doi.org/10.1001/jama.2020.2648.

[2] Richardson S, Hirsch JS, Narasimhan M, Crawford JM, McGinn T, Davidson KW, et al. Presenting Characteristics, Comorbidities, and Outcomes Among 5700 Patients Hospitalized With COVID-19 in the New York City Area. JAMA 2020. https://doi.org/10.1001/jama.2020.6775.

[3] Zhou F, Yu T, Du R, Fan G, Liu Y, Liu Z, et al. Clinical course and risk factors for mortality of adult inpatients with COVID-19 in Wuhan, China: a retrospective cohort study. The Lancet 2020;395:1054-62. https://doi.org/10.1016/S0140-6736(20)30566-3.

[4] Martín-Jiménez P, Muñoz-García MI, Seoane D, Roca-Rodríguez L, García-Reyne A, Lalueza A, et al. Cognitive Impairment Is a Common Comorbidity in Deceased COVID-19 Patients: A Hospital-Based Retrospective Cohort Study. J Alzheimers Dis 2020. https://doi.org/10.3233/JAD-200937.

[5] Atkins JL, Masoli JAH, Delgado J, Pilling LC, Kuo C-L, Kuchel GA, et al. Preexisting Comorbidities Predicting COVID-19 and Mortality in the UK Biobank Community Cohort. J Gerontol A Biol Sci Med Sci 2020;75:2224-30. https://doi.org/10.1093/gerona/glaa183.

[6] Matias-Guiu JA, Pytel V, Matías-Guiu J. Death Rate Due to COVID-19 in Alzheimer's Disease and Frontotemporal Dementia. J Alzheimers Dis 2020. https://doi.org/10.3233/JAD-200940.

[7] Bianchetti A, Rozzini R, Guerini F, Boffelli S, Ranieri P, Minelli G, et al. Clinical Presentation of COVID19 in Dementia Patients. J Nutr Health Aging 2020:1-3. https://doi.org/10.1007/s12603-0201389-1. 
[8] American Psychiatric Association: Diagnostic and Statistical Manual of Mental Disorder. ed 5. Arlington. American Psychiatric Publishing; 2013.

[9] Charlson ME, Pompei P, Ales KL, MacKenzie CR. A new method of classifying prognostic comorbidity in longitudinal studies: development and validation. J Chronic Dis 1987;40:373-83. https://doi.org/10.1016/0021-9681(87)90171-8.

[10] Khwaja A. KDIGO clinical practice guidelines for acute kidney injury. Nephron Clin Pract 2012;120:c179-184. https://doi.org/10.1159/000339789.

[11] Helms J, Kremer S, Merdji H, Clere-Jehl R, Schenck M, Kummerlen C, et al. Neurologic Features in Severe SARS-CoV-2 Infection. N Engl J Med 2020;382:2268-70.

https://doi.org/10.1056/NEJMc2008597.

[12] Garcez FB, Aliberti MJR, Poco PCE, Hiratsuka M, Takahashi S de F, Coelho VA, et al. Delirium and Adverse Outcomes in Hospitalized Patients with COVID-19. J Am Geriatr Soc 2020. https://doi.org/10.1111/jgs.16803.

[13] Witlox J, Eurelings LSM, de Jonghe JFM, Kalisvaart KJ, Eikelenboom P, van Gool WA. Delirium in elderly patients and the risk of postdischarge mortality, institutionalization, and dementia: a metaanalysis. JAMA 2010;304:443-51. https://doi.org/10.1001/jama.2010.1013.

[14] Inouye SK, Westendorp RGJ, Saczynski JS. Delirium in elderly people. Lancet 2014;383:911-22. https://doi.org/10.1016/S0140-6736(13)60688-1.

[15] Alkeridy WA, Almaglouth I, Alrashed R, Alayed K, Binkhamis K, Alsharidi A, et al. A Unique Presentation of Delirium in a Patient with Otherwise Asymptomatic COVID-19. J Am Geriatr Soc 2020. https://doi.org/10.1111/jgs.16536.

[16] Tay HS, Harwood R. Atypical presentation of COVID-19 in a frail older person. Age Ageing 2020. https://doi.org/10.1093/ageing/afaa068.

[17] Butt I, Sawlani V, Geberhiwot T. Prolonged Confusional state as first manifestation of COVID-19. Ann Clin Transl Neurol 2020. https://doi.org/10.1002/acn3.51067.

[18] Poloni TE, Carlos AF, Cairati M, Cutaia C, Medici V, Marelli E, et al. Prevalence and prognostic value of Delirium as the initial presentation of COVID-19 in the elderly with dementia: An Italian retrospective study. EClinicalMedicine 2020;26:100490. https://doi.org/10.1016/j.eclinm.2020.100490.

[19] Pieralli F, Vannucchi V, Mancini A, Grazzini M, Paolacci G, Morettini A, et al. Delirium is a predictor of in-hospital mortality in elderly patients with community acquired pneumonia. Intern Emerg Med 2014;9:195-200. https://doi.org/10.1007/s11739-013-0991-1. 
[20] Aliberti S, Bellelli G, Belotti M, Morandi A, Messinesi G, Annoni G, et al. Delirium symptoms during hospitalization predict long-term mortality in patients with severe pneumonia. Aging Clin Exp Res 2015;27:523-31. https://doi.org/10.1007/s40520-014-0297-9.

[21] Rogers JP, Chesney E, Oliver D, Pollak TA, McGuire P, Fusar-Poli P, et al. Psychiatric and neuropsychiatric presentations associated with severe coronavirus infections: a systematic review and meta-analysis with comparison to the COVID-19 pandemic. Lancet Psychiatry 2020. https://doi.org/10.1016/S2215-0366(20)30203-0.

[22] Aghagoli G, Gallo Marin B, Katchur NJ, Chaves-Sell F, Asaad WF, Murphy SA. Neurological Involvement in COVID-19 and Potential Mechanisms: A Review. Neurocrit Care 2020:1-10. https://doi.org/10.1007/s12028-020-01049-4.

[23] Holmes C, Cunningham C, Zotova E, Culliford D, Perry VH. Proinflammatory cytokines, sickness behavior, and Alzheimer disease. Neurology 2011;77:212-8. https://doi.org/10.1212/WNL.0b013e318225ae07.

[24] Kanberg N, Ashton NJ, Andersson L-M, Yilmaz A, Lindh M, Nilsson S, et al. Neurochemical evidence of astrocytic and neuronal injury commonly found in COVID-19. Neurology 2020;95:e1754-9. https://doi.org/10.1212/WNL.0000000000010111.

[25] Norman RE, Stall NM, Sinha SK. Typically Atypical: COVID-19 Presenting as a Fall in an Older Adult. Journal of the American Geriatrics Society 2020;68:E36-7. https://doi.org/10.1111/jgs.16526.

[26] van lersel MB, Hoefsloot W, Munneke M, Bloem BR, Olde Rikkert MGM. Systematic review of quantitative clinical gait analysis in patients with dementia. Z Gerontol Geriatr 2004;37:27-32. https://doi.org/10.1007/s00391-004-0176-7.

[27] Jensen J, Lundin-Olsson L, Nyberg L, Gustafson Y. Falls among frail older people in residential care. Scand J Public Health 2002;30:54-61.

[28] Ellul MA, Benjamin L, Singh B, Lant S, Michael BD, Easton A, et al. Neurological associations of COVID-19. Lancet Neurol 2020;19:767-83. https://doi.org/10.1016/S1474-4422(20)30221-0.

[29] Frontera JA, Sabadia S, Lalchan R, Fang T, Flusty B, Millar-Vernetti P, et al. A Prospective Study of Neurologic Disorders in Hospitalized COVID-19 Patients in New York City. Neurology 2020. https://doi.org/10.1212/WNL.0000000000010979.

[30] Canevelli M, Palmieri L, Raparelli V, Lo Noce C, Colaizzo E, Tiple D, et al. Prevalence and clinical correlates of dementia among COVID-19-related deaths in Italy. Alzheimers Dement (Amst) 2020;12. https://doi.org/10.1002/dad2.12114.

[31] Liu N, Sun J, Wang X, Zhao M, Huang Q, Li H. The Impact of Dementia on the Clinical Outcome of COVID-19: A Systematic Review and Meta-Analysis. J Alzheimers Dis 2020;78:1775-82. 
https://doi.org/10.3233/JAD-201016.

[32] Cummings MJ, Baldwin MR, Abrams D, Jacobson SD, Meyer BJ, Balough EM, et al. Epidemiology, clinical course, and outcomes of critically ill adults with COVID-19 in New York City: a prospective cohort study. Lancet 2020;395:1763-70. https://doi.org/10.1016/S0140-6736(20)31189-2.

[33] Lenze EJ, Mattar C, Zorumski CF, Stevens A, Schweiger J, Nicol GE, et al. Fluvoxamine vs Placebo and Clinical Deterioration in Outpatients With Symptomatic COVID-19: A Randomized Clinical Trial. JAMA 2020. https://doi.org/10.1001/jama.2020.22760.

\section{Tables}

Table 1- Characteristics of included patients 


\begin{tabular}{|c|c|c|c|c|}
\hline & $\begin{array}{l}\text { Total } \\
(\mathrm{n}=125)\end{array}$ & $\begin{array}{c}\text { Survivors } \\
(\mathrm{n}=97)\end{array}$ & $\begin{array}{l}\text { Non- } \\
\text { survivors }(n=28)\end{array}$ & $p$ \\
\hline Age & $86(82-91)$ & $87(82-91)$ & $86(82-93)$ & 0.815 \\
\hline Male sex & $41.6 \%(52)$ & $36.1 \%(35)$ & $60.7 \%(17)$ & 0.029 \\
\hline Admission from & & & & 0.663 \\
\hline Home & $59.2(74)$ & $57.7 \%(56)$ & $64.3 \%(18)$ & \\
\hline Long-term care facility & $40.8 \%(51)$ & $42.3 \%(41)$ & $35.7 \%(10)$ & \\
\hline \multicolumn{5}{|l|}{ Medical history } \\
\hline Comorbidities & $91.2 \%(114)$ & $91.8 \%(89)$ & $89.3 \%(25)$ & 0.709 \\
\hline$>2$ Comorbidities & $67.2 \%(84)$ & $67.0 \%(65)$ & $64.3 \%(18)$ & 0.822 \\
\hline Charlson Comorbidity Index & $6(5-7)$ & $6(5-7)$ & $6(5-7)$ & 0.292 \\
\hline \multicolumn{5}{|l|}{ Neurological status } \\
\hline \multicolumn{5}{|l|}{ Etiology of dementia } \\
\hline Unspecified cognitiv impairement & $60.0 \%(75)$ & $59.8 \%(58)$ & $60.7 \%(17)$ & 1.000 \\
\hline Diagnosed dementia & $40.0 \%(50)$ & $40.2 \%(39)$ & $39.3 \%(11)$ & 1.000 \\
\hline Alzheimers Disease & $10.4 \%(13)$ & $11.3 \%(11)$ & $7.1 \%(2)$ & 0.731 \\
\hline Vascular Dementia & $7.2 \%(9)$ & $6.2 \%(6)$ & $10.7 \%(3)$ & 0.418 \\
\hline Other causes of dementia & $7.2 \%(9)$ & $5.2 \%(5)$ & $14.3 \%(4)$ & 0.113 \\
\hline $\begin{array}{l}\text { Parkinson disease, parkinsonian } \\
\text { syndromes }\end{array}$ & $9.6 \%(12)$ & $10.3 \%(10)$ & $7.1 \%(2)$ & 1.000 \\
\hline Psychosis & $3.2 \%(4)$ & $4.1 \%(4)$ & $0.0 \%(0)$ & 1.000 \\
\hline Alcohol related dementia & $2.4 \%(3)$ & $3.1 \%(3)$ & $0.0 \%(0)$ & 1.000 \\
\hline \multicolumn{5}{|l|}{ Neurological symptoms\& history } \\
\hline Mood disorder & $31.2 \%(39)$ & $33.0 \%(32)$ & $25.0 \%(7)$ & 0.640 \\
\hline Psychotic symptoms & $12.0 \%(15)$ & $12.4 \%(12)$ & $10.7 \%(3)$ & 1.000 \\
\hline History of stroke & $32.0 \%(40)$ & $32.0 \%(31)$ & $32.1 \%(9)$ & 1.000 \\
\hline History of fall & $38.4 \%(48)$ & $36.1 \%(35)$ & $46.4 \%(13)$ & 0.373 \\
\hline Walk & $70.4 \%(88)$ & $70.1 \%(68)$ & $71.4 \%(20)$ & 1.00 \\
\hline Psychotrop Treatment & $60.0 \%(75)$ & $60.8 \%(59)$ & $57.1 \%(16)$ & 0.826 \\
\hline Anxiolytic & $30.4 \%(38)$ & $32.0 \%(31)$ & $25.0 \%(7)$ & 0.642 \\
\hline Antidepressant, mood regulator & $35.2 \%(44)$ & $35.1 \%(34)$ & $35.7 \%(10)$ & 1.000 \\
\hline Neuroleptics & $12.0 \%(15)$ & $11.3 \%(11)$ & $14.3 \%(4)$ & 0.742 \\
\hline \multicolumn{5}{|l|}{ Non neurological comorbidities } \\
\hline Cardiovascular disease & $40.8 \%(51)$ & $38.1 \%(37)$ & $50.0 \%(14)$ & 0.383 \\
\hline Arterial hypertension & $80.0 \%(100)$ & $79.4 \%(77)$ & $82.1 \%(23)$ & 1.00 \\
\hline Hypercholesterolemia & $48.8 \%(61)$ & $46.4 \%(45)$ & $57.1 \%(16)$ & 0.392 \\
\hline Atrial fibrillation & $24.8 \%(31)$ & $24.7 \%(24)$ & $25.0 \%(7)$ & 1.00 \\
\hline Coronaropathy & $16.0 \%(20)$ & $14.4 \%(14)$ & $21.4 \%(6)$ & 0.388 \\
\hline Cardiac insuffisancy & $24.0 \%(30)$ & $25.8 \%(25)$ & $17.9 \%(5)$ & 0.460 \\
\hline Thrombosis & $9.6 \%(12)$ & $11.3 \%(11)$ & $3.6 \%(1)$ & 0.296 \\
\hline COPD & $8.8 \%(11)$ & $6.2 \%(6)$ & $17.9 \%(5)$ & 0.068 \\
\hline Respiratory insuffisancy & $3.2 \%(4)$ & $3.1 \%(3)$ & $3.6 \%(1)$ & 1.000 \\
\hline Diabete & $16.8 \%(21)$ & $15.5 \%(15)$ & $21.4 \%(6)$ & 0.566 \\
\hline Denutrition & $33.6 \%(42)$ & $37.1 \%(36)$ & $21.4 \%(6)$ & 0.172 \\
\hline Malignancy & $9.6 \%(12)$ & $11.3 \%(11)$ & $3.6 \%(1)$ & 0.296 \\
\hline Chronic liver disease & $1.6 \%(2)$ & $2.1 \%(2)$ & $0.0 \%(0)$ & 1.000 \\
\hline Chronic renal disease & $16.0 \%(20)$ & $11.3 \%(11)$ & $32.1 \%(9)$ & 0.017 \\
\hline
\end{tabular}

Data are median (IQI), \%(n). P values $>0.05$ [Bold] indicates significant differences between survivors and nonsurvivors. 
*Other causes of dementia: included mixed dementia (AD \& vascular dementia, $n=7$ ), Fronto temporal dementia ( $\mathrm{n}=1$ ) and vascular dementia and alcohol-related dementia $(n=1)$

COPD: Chronic Obstructive Pulmonary Disease

\section{Table 2- COVID clinical symptoms and laboratory results}

\begin{tabular}{|c|c|c|c|c|}
\hline Symptoms at admission & Total (125) & Survivors $(n=97)$ & Non survivors $(n=28)$ & $\mathrm{P}$ \\
\hline Fever & $72.8 \%(91)$ & $71.1 \%(69)$ & $78.6 \%(22)$ & 0.482 \\
\hline Cough & $49.6 \%(62)$ & $51.5 \%(50)$ & $42.9 \%(12)$ & 0.521 \\
\hline Expectorations & $21.6 \%(27)$ & $18.6 \%(18)$ & $32.1 \%(9)$ & 0.190 \\
\hline Polypnea & $51.2 \%(64)$ & $42.3 \%(41)$ & $82.1 \%(23)$ & $<0.0001$ \\
\hline Desaturation & $50.4 \%(63)$ & $43.3 \%(42)$ & $75.0 \%(21)$ & 0.002 \\
\hline Minimum Saturation & $90(88-92)$ & $90(88-92)$ & $90(88-91)$ & 0.167 \\
\hline Digestive symptoms & $16.8 \%(21)$ & $18.6 \%(18)$ & $10.7 \%(3)$ & 0.400 \\
\hline Asthenia & $76.8 \%(96)$ & $72.2 \%(70)$ & $92.9 \%(26)$ & 0.023 \\
\hline Myalgia & $15.2 \%(19)$ & $15.5 \%(15)$ & $14.3 \%(4)$ & 1.000 \\
\hline Anorexia & $56.8 \%(71)$ & $53.6 \%(52)$ & $67.9 \%(19)$ & 0.201 \\
\hline Headache & $4.0 \%(5)$ & $4.1 \%(4)$ & $3.6 \%(1)$ & 0.688 \\
\hline Confusion, delirium & $82.4 \%(103)$ & $81.4 \%(79)$ & $85.7 \%(24)$ & 0.780 \\
\hline Initial fall & $35.2 \%(44)$ & $33.0 \%(32)$ & $42.9 \%(12)$ & 0.373 \\
\hline \multicolumn{5}{|l|}{ Laboratory findings } \\
\hline Hemoglobin, g/dL & $12.1(10.9-13.08)$ & $12.2(10.9-13.3)$ & $11.6(10.3-12.7)$ & 0.152 \\
\hline Lymphocytes count( mm3) & $0.99(0.73-1.29)$ & $1.0(0.8-1.3)$ & $0.9(0.6-1.2)$ & 0.032 \\
\hline Lymphopenia, \% & $84.8 \%(106)$ & $85.6 \%(83)$ & $82.1 \%(23)$ & 0.544 \\
\hline White blood cell count (mm3) & $5.8(3.9-7.9)$ & $5.4(3.9-7.1)$ & $6.2(4.1-8.7)$ & 0.070 \\
\hline Platelets count (mm3) & $207(164.3-265)$ & $210(170-261)$ & $202(150-283)$ & 0.995 \\
\hline Thrombopenia,\% & $16.0 \%(20)$ & $13.4 \%(13)$ & $25.0 \%(7)$ & 0.146 \\
\hline Initial C-reactive protein, $\mathrm{mg} / \mathrm{dL}$ & $30.85(8.75-84.75)$ & $25.8(8.0-64.5)$ & $76.0(33.0-44.0)$ & $<0.0001$ \\
\hline Initial Creatinine, $\mu \mathrm{mol} / \mathrm{L}$ & $78(64-103.8)$ & $74.0(63.5-94.0)$ & $127.0(70.0-159.0)$ & 0.003 \\
\hline Aspartate aminotransferase, U/L & $36(24-54)$ & $35(24-53)$ & $46(32-61)$ & 0.053 \\
\hline Alanine aminotransferase, U/L & $18(13-31)$ & $17.00(13.00-31.00)$ & $23.50(12.75-34.75)$ & 0.438 \\
\hline Albumin, $g / L$ & $30(26-34)$ & $30.8(27-34)$ & $28.5(23-33)$ & 0.088 \\
\hline Troponinin positivity, \%\# & $35.5 \%(22)$ & $30.4 \%(14)$ & $50.0 \%(8)$ & 0.032 \\
\hline
\end{tabular}

Data are presented as median (IQI), \%(n). P values $>0.05$ [Bold] indicates significant differences between survivors and non-survivors. \#:Troponine was available for 62 subjects.

Table 3- Treatement, complication and outcome 


\begin{tabular}{|c|c|c|c|c|}
\hline & Total & Survivor $(\mathrm{n}=97)$ & Non-survivors $(\mathrm{N}=28)$ & $\mathrm{P}$ \\
\hline Covid Severity* & & & & 0.001 \\
\hline Mild & $37.6 \%(47)$ & $48.5 \%(47)$ & $0.0 \%(0)$ & \\
\hline Moderate & $27.2 \%(34)$ & $35.0 \%(34)$ & $0.0 \%(0)$ & \\
\hline Severe & $35.2 \%(44)$ & $16.5 \%(16)$ & $100 \%(28)$ & \\
\hline \multicolumn{5}{|l|}{ Treatement } \\
\hline Oxygenotherapy & $60.0 \%(75)$ & $50.5 \%(49)$ & $92.9 \%(26)$ & $<0.0001$ \\
\hline Maximal flow (L/min) & $3.0(2.0-6.0)$ & $3.0(2.0-6.0)$ & $5.0(2.5-15.0)$ & 0.018 \\
\hline Antibiotherapy & $61.6 \%(77)$ & $57.7 \%(56)$ & $75.0 \%(21)$ & 0.074 \\
\hline Combination antibiotherapy & $33.6 \%(42)$ & $29.9 \%(29)$ & $46.4 \%(13)$ & 0.082 \\
\hline Betalactamine & $54.4 \%(68)$ & $50.5 \%(49)$ & $67.9 \%(19)$ & 0.079 \\
\hline Macrolides & $37.6 \%(47)$ & $35.1 \%(34)$ & $46.4 \%(13)$ & 0.279 \\
\hline 2nd line antibiotherapy & $17.6 \%(22)$ & $14.4 \%(14)$ & $28.6 \%(8)$ & 0.096 \\
\hline Steroids & $8.0 \%(10)$ & $8.2 \%(8)$ & $7.1 \%(2)$ & 1.000 \\
\hline Hydroxychloroquine & $16.8 \%(21)$ & $16.5 \%(16)$ & $17.9 \%(5)$ & 1.000 \\
\hline Neuroleptics & $4.8 \%(6)$ & $5.2 \%(5)$ & $3.6 \%(1)$ & 0.678 \\
\hline \multicolumn{5}{|l|}{ Complications } \\
\hline ARDS & $25.6 \%(32)$ & $6.2 \%(6)$ & $92.9 \%(26)$ & $<0.0001$ \\
\hline Cardiac injury & $13.6 \%(17)$ & $9.3 \%(9)$ & $28.6 \%(8)$ & 0.024 \\
\hline ACKI & $16.8 \%(21)$ & $12.4 \%(12)$ & $32.1 \%(9)$ & 0.021 \\
\hline Bacterial surinfection & $14.4 \%(18)$ & $11.3 \%(11)$ & $25.0 \%(7)$ & 0.122 \\
\hline Behavioral disorder & $19.2 \%(24)$ & $21.6 \%(21)$ & $10.7 \%(3)$ & 0.278 \\
\hline Diabetic acidocetosis & $2.4 \%(3)$ & $3.1 \%(3)$ & $0.0 \%(0)$ & 1.000 \\
\hline Seizure & $2.4 \%(3)$ & $2.1 \%(2)$ & $3.6 \%(1)$ & 0.536 \\
\hline Stroke & $2.4 \%(3)$ & $2.1 \%(2)$ & $3.6 \%(1)$ & 1.000 \\
\hline Outcome & Total & Survivor & Non survivor & \\
\hline Total mortality & $22.4 \%(28)$ & & & \\
\hline Delay admission-death & \multicolumn{4}{|c|}{$8.5(3.7-16)$} \\
\hline Lengh of stay & \multicolumn{3}{|c|}{$16(11-19.7)$} & \\
\hline Discharge home before end o & \multicolumn{3}{|c|}{ lowup $\quad 40.2 \%(39)$} & \\
\hline
\end{tabular}

Data are median (IQI), \%(n). P values >0.05 [Bold] indicates significant differences between survivors and nonsurvivors.

*COVID severity defined according to WHO guidelines

ACKI: Acute Kidney Injury; ARDS: Acute Respiratory Distress Syndrome 


\section{Table 4-Predictive factors of mortality at 21 days of diagnosis}

\begin{tabular}{|c|c|c|c|c|}
\hline & \multirow[t]{2}{*}{$\operatorname{Exp}(B)$} & \multicolumn{2}{|c|}{ 95\% C.I.for $\operatorname{EXP}(B)$} & \multirow[t]{2}{*}{ Sig. } \\
\hline & & Lower & Upper & \\
\hline Male sexe & 1.120 & 0.379 & 3.310 & 0.838 \\
\hline Chronic renal disease & 4.631 & 1.215 & 17.649 & 0.025 \\
\hline Desaturation & 1.879 & 0.418 & 8.452 & 0.411 \\
\hline Dyspnea & 2.100 & 0.452 & 9.765 & 0.344 \\
\hline Lymphocytes & 1.096 & 0.649 & 1.852 & 0.732 \\
\hline Creatinine & 0.999 & 0.992 & 1.007 & 0.850 \\
\hline CRP & 1.013 & 1.004 & 1.021 & 0.004 \\
\hline
\end{tabular}

Multivaritate binary logistic regression for identifying predictive factors of outcome. Troponine was excluded of the analysis due to missing data.P<0.05 indicates significance [Bold]

95\%CI: 95\% Confidence Interval. CRP: C-reactive Protein 